\title{
Pleth variability index versus pulse pressure variation for intraoperative goal-directed fluid therapy in patients undergoing low- to-moderate risk abdominal surgery: a randomized controlled trial
}

\author{
Sean Coeckelenbergh ${ }^{1,2^{*}+}$ D. Amélie Delaporte ${ }^{1,2+}$, Djamal Ghoundiwal ${ }^{1,2}$, Javad Bidgoli, ${ }^{1,2}$, Jean-François Fils ${ }^{1,3}$,
} Denis Schmartz ${ }^{1,2}$ and Philippe Van der Linden ${ }^{1,2}$

\begin{abstract}
Background: Goal-directed fluid therapy (GDFT) based on dynamic indicators of fluid responsiveness has been shown to decrease postoperative complications and hospital length of stay (LOS) in patients undergoing major abdominal surgery. The usefulness of this approach still needs to be clarified in low-to-moderate risk abdominal surgery. Both pulse-pressure variation (PPV) and pleth variability index (PVI) can be used to guide GDFT strategies. The objective of this prospective randomized controlled trial was to determine if the use of PVI guided GDFT, when compared to PPV guided GDFT, would lead to similar hospital LOS in patients undergoing low-to-moderate risk surgery. Secondary outcomes included amount of fluid administered and incidence of postoperative complications.

Methods: Patients were randomized into either PVI or PPV guided GDFT groups. Both received a baseline $2 \mathrm{ml} \mathrm{kg}^{-1} \mathrm{~h}^{-1}$ Lactated Ringer infusion. Additional fluid boluses consisted of $250 \mathrm{~mL}$ of colloid that was infused over a 10 min period if PVI was $>15 \%$ or PPV was $>13 \%$ for at least five minutes. The primary outcome was to determine if hospital LOS, which was defined as the number of days from surgery up to the day the surgeon authorized hospital discharge, was equivalent between the two groups.

Results: A total of 76 patients were included and they were randomized into two groups of 38 patients. Baseline characteristics were similar in both groups. Both PVI and PPV guided GDFT strategies were equivalent for the primary outcome of LOS (median [interquartile range]) (days) 2.5 [2.0-3.3] vs. 3.0 [2.0-5.0], $p=0.230$, respectively. Fluids infused, postoperative complications, and all other outcomes were not different between groups.

Conclusion: In patients undergoing low-to-moderate risk abdominal surgery, PVI seems to guide GDFT similarly to PPV in regards to hospital LOS, amount of fluid, and incidence of postoperative complications. However, in low-risk patients undergoing these surgical procedures optimizing stroke volume may have limited impact on outcome.
\end{abstract}

Trial registration: ClinicalTrials.gov Identifier: NCT02908256, September 2016, retrospectively registered.

Keywords: Anesthesia, Anesthesiology, Goal-directed therapy, Colloids, Crystalloids, Fluid responsiveness, Hemodynamics

\footnotetext{
* Correspondence: secoecke@ulb.ac.be

${ }^{\dagger}$ Sean Coeckelenbergh and Amélie Delaporte contributed equally to this

work.

'Department of Anesthesiology, CHU Brugmann, 4, Place Van Gehuchten,

1020 Bruxelles, Belgium

${ }^{2}$ Université Libre de Bruxelles, Brussels, Belgium

Full list of author information is available at the end of the article
}

(c) The Author(s). 2019 Open Access This article is distributed under the terms of the Creative Commons Attribution 4.0 International License (http://creativecommons.org/licenses/by/4.0/), which permits unrestricted use, distribution, and reproduction in any medium, provided you give appropriate credit to the original author(s) and the source, provide a link to the Creative Commons license, and indicate if changes were made. The Creative Commons Public Domain Dedication waiver (http://creativecommons.org/publicdomain/zero/1.0/) applies to the data made available in this article, unless otherwise stated. 


\section{Background}

Goal-directed fluid therapy (GDFT), guided by dynamic indicators of fluid responsiveness, (e.g. pulse pressure variation (PPV)) has been shown to decrease postoperative complications and to shorten length of stay (LOS) during major abdominal surgery [1-3]. Dynamic indicators are based on cardiopulmonary interactions during mechanical ventilation and predict fluid responsiveness better than static indicators (e.g. central venous pressure and non-invasive blood pressure) [4-8].

Pulse pressure variation can guide GDFT [9], but it requires the insertion of an arterial catheter and its inherent risks [10]. This is not always desirable, especially for low-to-moderate risk surgeries where blood loss and fluid shifts are minimal. In cases where the risks of an invasive catheter outweigh its potential benefits, pleth variability index (PVI) may be a valuable alternative. PVI is a totally non-invasive monitor which only requires a pulse oximeter [11]. PVI-based GDFT has been shown to reduce postoperative lactate levels and improve postoperative outcome in patients undergoing high-risk abdominal surgery [12-14]. It is safe, easily implemented, and non-invasive. Nevertheless, PVI's correlation to PPV has been shown to be weak during major abdominal surgery and cardiac surgery, which may be due to intraoperative or chronic changes in arteriolar compliance, sympathetic tone, and heart rate variability $[15,16]$. In low-to-moderate risk abdominal surgery, however, such effects on arteriolar and sympathetic tone are probably less frequent and the clinical impact of PVI remains to be determined. PVI may thus be useful in guiding GDFT in this population where these hemodynamic alterations are scarce.

The primary objective of this prospective randomized controlled trial was to demonstrate that the use of PVI guided GDFT and PPV guided GDFT would lead to equivalent hospital LOS in patients undergoing low-to-moderate risk abdominal surgery. Secondary objectives included the amount of fluid administered and the incidence of postoperative complications associated to each GDFT strategy.

\section{Methods}

This single center prospective parallel group randomized controlled trial was performed at the CHU-Brugmann Hospital after ethical committee approval (Brussels, Belgium) ( ${ }^{\circ} \mathrm{CE} / 201134$ and $\left.\mathrm{B} 077201112471\right)$ and was registered on clinicaltrials.gov (NCT02908256). Patients gave written informed consent, were adults scheduled for elective low-to-moderate risk abdominal surgery lasting at least one hour, and were allocated into each group after randomization with a ratio of 1:1. Patients were randomized with internet-based software (http://www. randomization.com) and the determined groups were placed in numbered sealed envelopes. AD and DG generated the randomization sequence, enrolled patients, and assigned patients to the interventions. Exclusion criteria consisted of patients younger than 18 years, American Society of Anesthesiologist physical status score greater than III, a body mass index $>35 \mathrm{~kg} \mathrm{~m}^{-2}$, chronic cardiac arrhythmias, altered myocardial function (left ventricular ejection fraction $<25 \%$ ), peripheral vascular disease, severe respiratory disease, gelatin allergy, and end stage renal failure (creatinine clearance $<30 \mathrm{ml} \mathrm{min}^{-1}$ ).

\section{Anesthesia protocol}

Patients fasted at least $6 \mathrm{~h}$ for solids and $2 \mathrm{~h}$ for clear liquids preoperatively and received oral alprazolam $0.5 \mathrm{mg}$ one hour before induction of general anesthesia. Patient monitoring included 5 lead electrocardiogram, non-invasive blood pressure, and peripheral pulse oximetry. The Masimo Radical 7 Set pulse oximeter (Masimo Corp, Irvine, CA, USA) was applied on the index finger, contralateral to the blood pressure cuff, and covered from ambient light for the continuous monitoring of the PVI. A 20-G radial artery catheter was placed ipsilateral to the pulse oximeter after induction of anesthesia. PPV were displayed on the IntelliVue MP5 monitor (Philips Healthcare, Best, Netherlands). Investigators were blinded to the values not pertaining to the allocated GDFT protocol. Entropy sensors (GE Healthcare, Chalfont St Giles, United Kingdom) monitored anesthesia depth and values were kept between 40 and 60 for all patients. Anesthetists induced anesthesia with a propofol bolus of $1-2 \mathrm{mg} \mathrm{kg}^{-1}$ and a sufentanil $0.3 \mathrm{ng} \mathrm{ml}^{-1}$ target controlled infusion Gepts model [17] (Alaris PK syringe pump, CardinalHealth, Rolle, Switzerland). Rocuronium $0.5 \mathrm{mg} \mathrm{kg}^{-1}$ facilitated oral tracheal intubation and muscle paralysis was maintained with additional doses of $0.1 \mathrm{mg} \mathrm{kg}^{-1}$ to maintain a train of four ratio of 0:4 (TOF Watch, Alsevia Pharma, France). Anesthesia was maintained with sevoflurane and sufentanil with a target concentration of $0.2 \mathrm{ng} \mathrm{ml}^{-1}$. Rectal temperature was measured continuously and a forcedair warming blanket was added to maintain normothermia. Tidal volume was maintained at of $8 \mathrm{ml} \mathrm{kg}^{-1}$ of ideal body weight and the respiratory frequency was set to maintain expiratory carbon dioxide between 30 and $35 \mathrm{mmHg}$. Positive end-expiratory pressure was set to $5 \mathrm{~cm} \mathrm{H}_{2} \mathrm{O}$ in all patients. Trendelenburg was set at $10^{\circ}$ using a goniometer (iPhone, Apple, Cupertino, CA, USA) that was placed lateral to each patient's head. Postoperative pain control was achieved with the following analgesics (if not contraindicated): paracetamol, diclofenac, tramadol, and patient controlled intravenous morphine. Use of nitrous oxide, ketamine, or clonidine was prohibited intraoperatively.

\section{GDFT protocol}

Patients were randomized into either PPV GDFT or PVI GDFT groups. Anesthetists were blinded to the monitor 
not corresponding to their allocated group while patients and postoperative care givers were blinded to the intervention. All patients received a baseline $2 \mathrm{ml} \mathrm{kg}^{-1} \mathrm{~h}^{-1}$ Lactated Ringer infusion. The fluid challenge consisted of a $250 \mathrm{ml}$ bolus of colloid (Geloplasma, Fresenius Kabi $\mathrm{SA}$, Belgium) that was infused over a $10 \mathrm{~min}$ period. Patients in the PVI GDFT group received a fluid challenge if PVI was higher than $15 \%$ for more than 5 min while patients in the PPV GDFT group received a fluid challenge if PPV was higher than $13 \%$ for more than $5 \mathrm{~min}$ $[11,18,19]$. Boluses were repeated until patients were no longer over the PVI or PPV fluid challenge thresholds. Phenylephrine was titrated if mean arterial blood pressure remained below $65 \mathrm{mmHg}$ despite preload optimization (i.e. PVI or PPV values were below the predetermined fluid responsiveness threshold) (Fig. 1). Additional crystalloids infused for antibiotic and analgesic administration were recorded and added to the total infused volume. Management of acute hemodynamic instability associated with hemorrhage was left at the attending anesthesiologist's discretion. There was no change in threshold values during pneumoperitoneum and the GDFT protocols were the same regardless of the use of laparoscopy.

\section{Outcomes variables}

The primary outcome was hospital the LOS, which was defined as the number of days from surgery up to the day the surgeon authorized hospital discharge. If patients remained hospitalized longer than the date decided by the surgeon, the surgical discharge date noted in the medical record was still used to calculate hospital LOS. Other outcomes included total infused colloid, total infused crystalloid, estimated blood loss, diuresis, intraoperative use of phenylephrine (i.e., mean arterial blood pressure remained below $65 \mathrm{mmHg}$ despite preload optimization), post-anesthesia care unit (PACU) LOS, number of anti-emetics administered at the PACU, post-operative complications (Additional file 1), time to first ambulation, and postoperative day 1 pain evaluation using visual analogue scale score.

\section{Statistical analysis}

The primary objective of the study was to demonstrate that hospital LOS was equivalent between the two groups. For a difference of one day and equivalence margin of two days a study with a power of $90 \%$ and an alpha of 0.01 would require 30 patients per group. Since we estimated a drop-out rate of about $20 \%$, we elected to recruit 38 patients per group. The R package TrialSize was used based on the work of Chow et al. [20]. We planned to determine if groups had comparable variances with Bartlett's test for homogeneity of variance and if the residuals of the t-test were normally distributed. In the case of non-normal distribution, a non-parametric approach would be used with the $\mathrm{R}$ package nparcomp [21] to take into account the non-parametric Behrens-Fisher problem [22]. This package tests whether the observations in one group tend to be different than those of another. If the $95 \%$ confidence

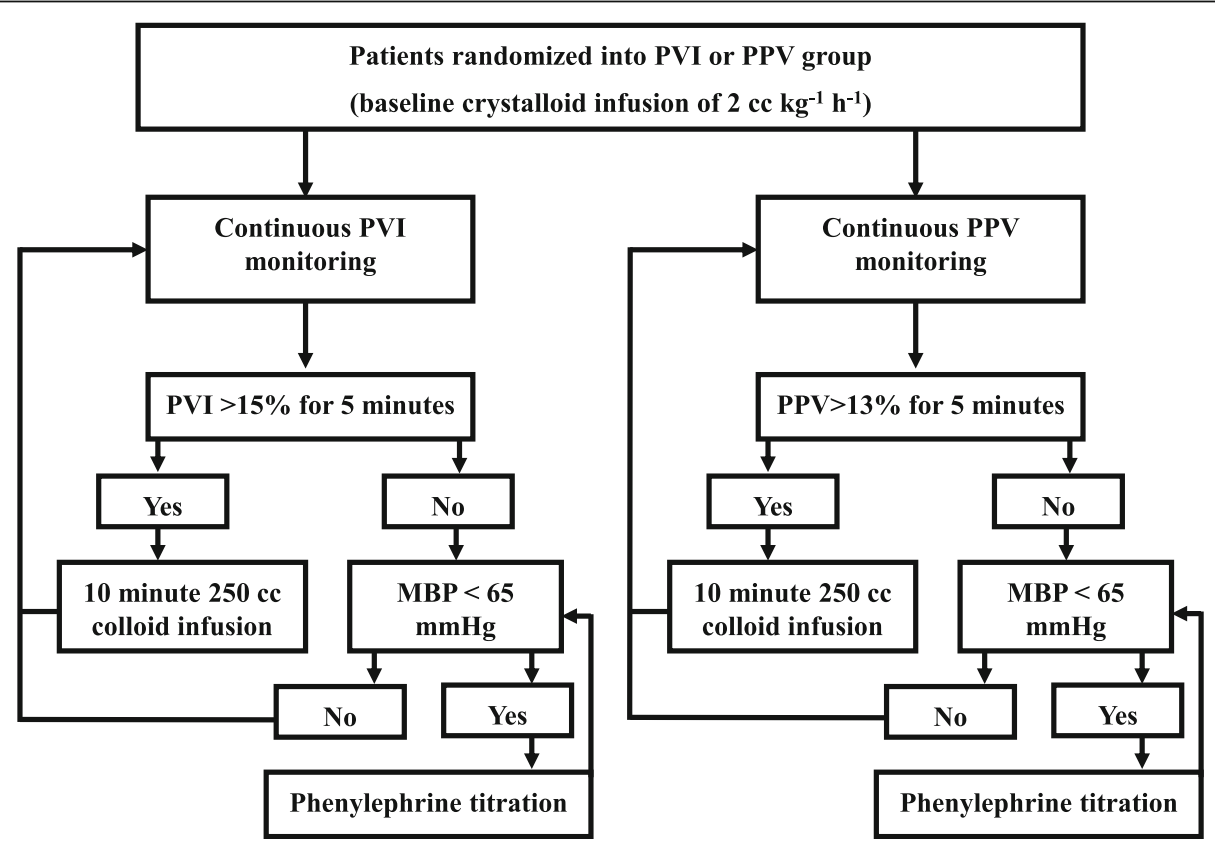

Fig. 1 Goal-directed fluid therapy protocols. Patients were randomized into either PVI or PPV guided groups. PPV pulse pressure variation, PVI Pleth variability index 
interval does not contain 0.5 the two groups are significantly different.

The Schapiro-Wilk test determined normality for continuous variables. Normally distributed variables were analyzed with student-t test and non-normal variables were analyzed with Mann-Whitney U test. Categorical variables were analyzed with Chi-square. Statistics were carried out using Minitab statistical software (Paris, France). Group allocation was revealed after data analysis.

\section{Results}

A total of 76 patients of the initially 129 screened patients were included from July 2011 to October 2013 (Fig. 2). Baseline characteristics were similar in both groups (Table 1). Anesthesia and surgical times were similar between groups. Patients remained in their preassigned group throughout the study period. Bartlett's test of homogeneity of variance $\left(\mathrm{Chi}^{2}=19.69, \mathrm{df}=1\right.$, $p$-value $<0.001)$ indicated that variances were not equal between groups and the Shapiro-Wilk normality test indicated that the residuals were not normally distributed for LOS. Therefore, the non-parametric approach was applied, and no difference was observed for the primary outcome of LOS (median [interquartile range]) 2.5 [2.0$3.3]$ vs. 3.0 [2.0-5.0] days, $p=0.230$, for PVI and PPV, respectively (Fig. 3). The $95 \%$ confidence interval equals [0.291-0.549]. Since it contains the 0.5 value, the two groups are equivalent for LOS.

Infused crystalloid volume, infused colloid volumes, estimated blood loss, diuresis, time to first ambulation, and pain evaluation at post-operative day 1 were not different between groups (Table 2). The use of phenylephrine to correct hypotension in preload optimized patients was not different between groups. There was no difference in individual postoperative complications or composite postoperative complications. None of the patients required supplementary fluids due to hemorrhage associated hemodynamic instability. No harm was caused by the intervention and no patient died during the study period. No correction was done for missing data.

\section{Discussion}

In patients undergoing low-to-moderate risk abdominal surgery PVI and PPV guided GDFT are considered equivalent for the primary outcome of hospital LOS and no difference was found between the secondary outcomes. Both strategies seem to optimize preload equally and lead to similar outcome. PVI nonetheless has the distinct advantages of being totally non-invasive. Although PPV can be displayed continuously with certain monitors, it is invasive and does not improve outcome when compared to PVI in this population.

Several studies have shown that PVI guided GDFT, when compared to fluid therapy guided by static parameters of fluid responsiveness, can lead to decreased infused fluid volume, decreased time to first stool, and decreased perioperative lactate levels [12, 13, 23, 24]. Trials comparing different GDFT strategies to PVI, such as esophageal Doppler, have however resulted in conflicting results. For

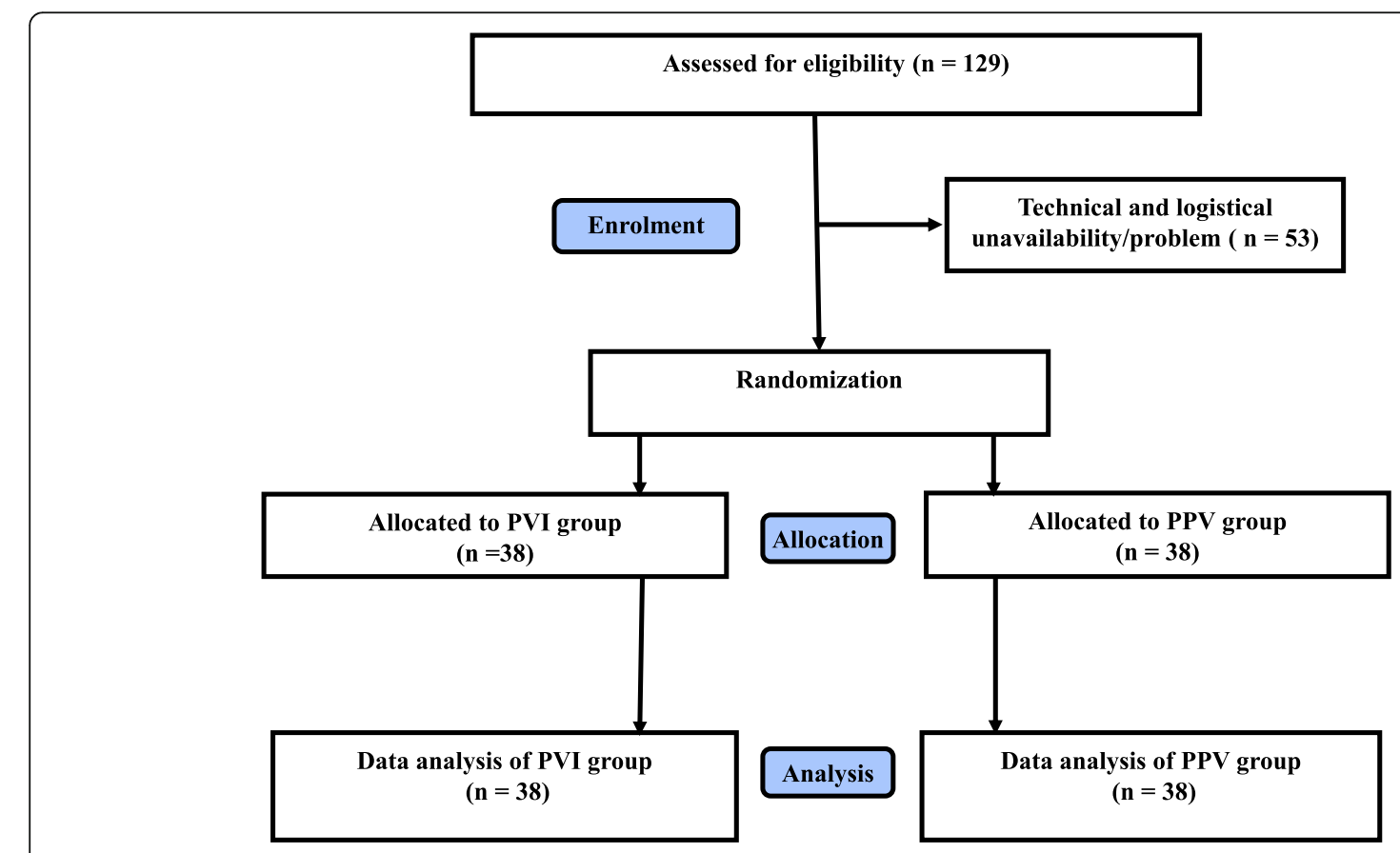

Fig. 2 Flow chart of enrolment, allocation, and analysis 
Table 1 Baseline characteristics, expressed as \% (number), mean (+/-SD), or median [IRQ]

\begin{tabular}{|c|c|c|c|}
\hline & $\mathrm{PVI}(n=38)$ & $\operatorname{PPV}(n=38)$ & $p$-value \\
\hline Age (year) & $45(+/-13)$ & $50(+/-13)$ & 0.124 \\
\hline Female gender & $92.1(35)$ & $94.7(36)$ & 0.644 \\
\hline Weight (kg) & $72(+/-15)$ & $66(+/-15)$ & 0.096 \\
\hline ASA Score & & & 0.154 \\
\hline ASA physical status 1 & $29.0(11)$ & $44.7(17)$ & \\
\hline ASA physical status 2 & $71.1(27)$ & $55.3(21)$ & \\
\hline \multicolumn{4}{|l|}{ Medications \% } \\
\hline Aspirin & $2.6(1)$ & $10.5(4)$ & 0.165 \\
\hline Beta-blocker & $13.2(5)$ & $10.5(4)$ & 0.723 \\
\hline ACEI & $7.9(3)$ & $2.6(1)$ & 0.304 \\
\hline ARB & $5.3(2)$ & $5.3(2)$ & 1.00 \\
\hline Calcium channel blocker & $5.3(2)$ & $2.6(1)$ & 0.556 \\
\hline SSRI & $5.3(2)$ & $5.3(2)$ & 1.000 \\
\hline Antidepressant other & $15.8(6)$ & $7.9(3)$ & 0.287 \\
\hline Benzodiazepine & $13.2(5)$ & $15.8(6)$ & 0.744 \\
\hline Hypertension & $31.6(12)$ & $15.8(6)$ & 0.105 \\
\hline Diabetes & $5.3(2)$ & $2.6(1)$ & 0.556 \\
\hline Obstructive pulmonary & $5.3(2)$ & $13.2(5)$ & 0.234 \\
\hline Previous major surgery & $21.1(8)$ & $23.7(9)$ & 0.783 \\
\hline Type of surgery & & & 0.312 \\
\hline Laparoscopy (\%) & $65.8(25)$ & $76.3(29)$ & \\
\hline Laparotomy (\%) & $34.2(13)$ & $23.7(9)$ & \\
\hline Surgery Duration (min) & $130(+/-75)$ & $122(+/-47)$ & 0.599 \\
\hline Anesthesia Time (min) & 180 [136-215] & 183 [142-229] & 0.670 \\
\hline
\end{tabular}

ASA American Society of Anesthesiology, ACEl angiotensin converting enzyme inhibitor, $A R B$ aldosterone receptor blocker, SSRI selective serotonin reuptake inhibitor example, when compared to esophageal Doppler in patients requiring renal transplantation, PVI was shown to detect fluid responsiveness less consistently [25]. These patients may have pathological endothelial changes affecting arterial compliance that lead to poor capillary distribution. Since PVI is a direct measure of arterial compliance [26], these effects may alter the fluid response threshold. However, when compared to esophageal Doppler GDFT in patients requiring colorectal resection, a population more comparable to ours, fluid administration and outcome was not different [27]. Bahlmann et al. also showed that PVI and stroke volume optimization assessed by esophageal Doppler during open abdominal surgery had similar outcome [28]. Our results parallel the latter studies and indicate that in low-to-moderate risk abdominal surgery, PVI seems to be an adequate guide for GDFT.

It is important to consider, nevertheless, that low-tomoderate risk abdominal surgery may itself explain the lack of difference between groups. Two recent studies on the impact of non-invasively guided GDFT (Clearsight/ ccNexfin) in patients undergoing moderate risk abdominal surgery, when compared to restrictive fluid therapy, were unable to demonstrate any difference between groups $[29,30]$. Two possible reasons for these findings are that the non-invasive monitor did not adequately optimize cardiac output or that preload optimization has little impact on outcome in low-to-moderate risk abdominal surgery. However, other studies focusing on low-to-moderate risk abdominal surgery reported that perioperative fluid management could still have an impact on postoperative outcome in this particular population indicating that fluid administration should be individualized and goal directed [31].

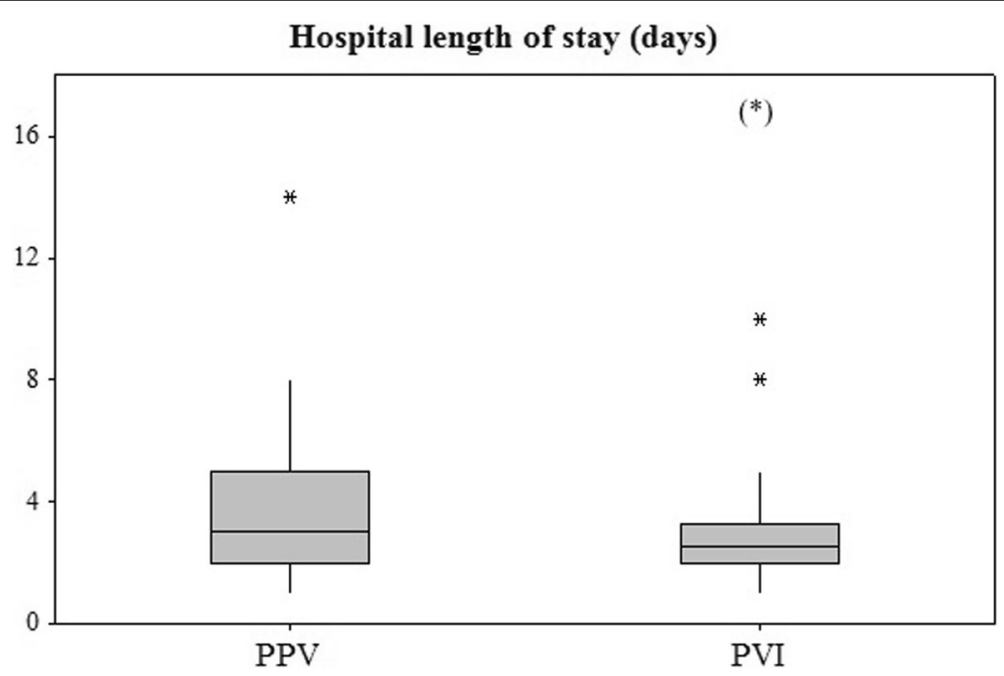

Fig. 3 Box-plot comparison of the primary outcome, length of stay (LOS). $\left(^{*}\right)$ In order to improve readability, one outlier (LOS $=35$ days) is not represented in this figure 
Table 2 Study outcomes, expressed as \% (number), mean (+/-SD), or median [IRQ]

\begin{tabular}{|c|c|c|c|}
\hline & PVI & PPV & $p$-value \\
\hline \multicolumn{4}{|l|}{ Intraoperative data } \\
\hline Total colloid (ml) & $500[0-750]$ & $250[0-500]$ & 0.275 \\
\hline Total crystalloid (ml) & $500[350-740]$ & 550 [450-663] & 0.458 \\
\hline Estimated blood loss (ml) & $100[50-300]$ & $100[50-163]$ & 0.445 \\
\hline Urine output (ml) & 150 [79-250] & 150 [100-250] & 0.803 \\
\hline Intraoperative phenylephrine & $26.3(10)$ & $21.1(8)$ & 0.589 \\
\hline \multicolumn{4}{|l|}{ Postoperative data } \\
\hline LOS PACU (min) & 105 [90-135] & 90 [45-135] & 0.382 \\
\hline PACU PONV & $10.5(4)$ & $7.9(3)$ & 0.692 \\
\hline Number of antiemetics PACU & & & 0.330 \\
\hline 0 & $89(34)$ & $92(35)$ & \\
\hline 1 & $5.3(2)$ & $7.9(3)$ & \\
\hline 2 & $5.3(2)$ & $0(0)$ & \\
\hline Hypotension PACU & $5.3(2)$ & $7.9(3)$ & 0.644 \\
\hline VAS Day 1 score & $1[0-2]$ & $2[0-2]$ & 0.925 \\
\hline Ward PONV & $7.9(3)$ & $7.9(3)$ & 1.000 \\
\hline Fever & $7.9(3)$ & $2.6(1)$ & 0.304 \\
\hline Post-operative complications & $4(10.5)$ & $2(5.3)$ & 0.395 \\
\hline Time to first ambulation & $1[1-2]$ & $2[1-2]$ & 0.231 \\
\hline
\end{tabular}

LOS length of stay, PONV postoperative nausea or vomiting, PACU post anesthesia care unit, VAS visual analogue scale

This randomized controlled trial had several limitations. In addition to the limitations intrinsic to a single center study, we did not measure protocol compliance, which is a key predictor of GDFT impact [3]. However, since both interventions required similar workloads, compliance should have been similar in both groups. In addition, this study was performed according to an intention to treat analysis and our results consequently reflect clinical practice. The vast majority of patients were women undergoing laparoscopic surgery and this should be noted when applying our GDFT strategies to patients. Another limitation inherent to PVI is its dependence on perfusion index, which varies depending on vascular tone [32]. This limitation nonetheless does not seem to have had an impact on our results since no difference was found between PVI and PPV groups in the amount of fluids administered or on outcome in this overwhelmingly healthy population. Another important point to consider is that this lack of difference between groups may be due to the low impact of GDFT on outcome in the studied population which ultimately consisted of low-risk patients undergoing low-to-moderate risk surgery. Nevertheless, physicians who still wish to implement a GDFT strategy for these patients should prefer a non-invasive monitor, such as PVI, to a more invasive monitor.

\section{Conclusion}

In patients undergoing low-to-moderate risk abdominal surgery, PVI seems to guide GDFT similarly to PPV in regards to hospital LOS, amount of fluid, and incidence of postoperative complications. However, in low-risk patients undergoing these surgical procedures optimizing stroke volume may have limited impact on outcome.

\section{Additional file}

Additional file 1: Definitions of postoperative complications. (DOCX 19 kb)

\section{Abbreviations}

ACEl: Angiotensin converting enzyme inhibitor; ARB: Aldosterone receptor blocker; ASA: American Society of Anesthesiology; GDFT: Goal-directed fluid therapy; LOS: Length of stay; PACU: Post anesthesia care unit; PPV: Pulse pressure variation; PVI: Pleth variability index; SSRI: Selective serotonin reuptake inhibitor; VAS: Visual analogue scale

\section{Acknowledgements}

The authors would like to acknowledge the medical and nursing staff of Brugmann $\mathrm{CHU}$ for their help in assuring the highest quality of care to all patients.

\section{Funding}

This study was funded solely by departmental resources.

Availability of data and materials

Study data is available upon contact of Dr. Sean Coeckelenbergh by email.

Authors' contributions

SC: Study design, data collection, data analysis, initial draft, approval of manuscript. AD: Study design, patient recruitment, data collection, critical revision and approval of manuscript. DG: Study design, patient recruitment, data collection, critical revision and approval of manuscript. JB: Study design, patient recruitment, data collection, critical revision and approval of manuscript. JFF: data analysis, critical revision and approval of manuscript. DS: data analysis, critical revision and approval of manuscript. PVdL: Study design, data collection, data analysis, initial draft, approval of manuscript. All authors have read and approved the manuscript.

\section{Ethics approval and consent to participate}

This study was approved by the CHU Brugmann ethical committee and patients gave written informed consent.

Consent for publication

not applicable

\section{Competing interests}

The authors declare that they have no competing interests.

\section{Publisher's Note}

Springer Nature remains neutral with regard to jurisdictional claims in published maps and institutional affiliations.

\section{Author details}

${ }^{1}$ Department of Anesthesiology, CHU Brugmann, 4, Place Van Gehuchten, 1020 Bruxelles, Belgium. ${ }^{2}$ Université Libre de Bruxelles, Brussels, Belgium. ${ }^{3}$ Ars Statistica SPRL, Nivelles, Belgium.

Received: 10 September 2018 Accepted: 1 March 2019 Published online: 09 March 2019

\section{References}

1. Salzwedel C, Puig J, Carstens A, Bein B, Molnar Z, Kiss K, Hussain A, Belda J, Kirov MY, Sakka SG, Reuter DA. Perioperative goal-directed hemodynamic therapy based on radial arterial pulse pressure variation and continuous cardiac index trending reduces postoperative complications after major 
abdominal surgery: a multi-center, prospective, randomized study. Crit Care. 2013;17(5):R191.

2. Joosten A, Coeckelenbergh S, Delaporte A, Ickx B, Closset J, Roumeguere T, Barvais L, Van Obbergh L, Cannesson M, Rinehart J, Van der Linden P. Implementation of closed-loop-assisted intra-operative goal-directed fluid therapy during major abdominal surgery: a case-control study with propensity matching. Eur J Anaesthesiol. 2018;35(9):650-8.

3. Pearse RM, Harrison DA, MacDonald N, Gillies MA, et al. Effect of a perioperative, cardiac output-guided hemodynamic therapy algorithm on outcomes following major gastrointestinal surgery: a randomized clinical trial and systematic review. JAMA. 2014;311(21):2181-90.

4. Lee S, Chun Y, Oh Y, Shin S, Park S, Kim S, Choi Y. Prediction of fluid responsiveness in the beach chair position using dynamic preload indices. J Clin Monit Comput. 2016;30(6):995-1002.

5. Wu C, Cheng Y, Liu Y, Wu T, Chien C, Chan K. Predicting stroke volume and arterial pressure fluid responsiveness in liver cirrhosis patients using dynamic preload variables: a prospective study of diagnostic accuracy. Eur J Anaesthesiol. 2016;33(9):645-52.

6. Vos JJ, Kalmar AF, Struys MM, Wietasch JK, Hendriks HG, Scheeren TW. Comparison of arterial pressure and plethysmographic waveform-based dynamic preload variables in assessing fluid responsiveness and dynamic arterial tone in patients undergoing major hepatic resection. $\mathrm{Br} J$ Anaesth. 2013;110(6):940-6

7. Lu W, Dong J, Xu Z, Shen H, Zheng J. The pleth variability index as an indicator of the central extracellular fluid volume in mechanically ventilated patients after anesthesia induction: comparison with initial distribution volume of glucose. Med Sci Monit. 2014;20:386-92.

8. van der Zee EN, Egal M, Gommers D, Groeneveld AB. Targeting urine output and 30-day mortality in goal-directed therapy: a systematic review with meta-analysis and meta-regression. BMC Anesthesiol. 2017;17(1):22.

9. Benes J, Giglio M, Brienza N, Michard F. The effects of goal-directed fluid therapy based on dynamic parameters on post-surgical outcome: a metaanalysis of randomized controlled trials. Crit Care. 2014;18(5):584.

10. Scheer B, Perel A, Pfeiffer UJ. Clinical review: complications and risk factors of peripheral arterial catheters used for haemodynamic monitoring in anaesthesia and intensive care medicine. Crit Care. 2002:6(3):199-204.

11. Cannesson M, Desebbe O, Rosamel P, Delannoy B, et al. Pleth variability index to monitor the respiratory variations in the pulse oximeter plethysmographic waveform amplitude and predict fluid responsiveness in the operating theatre. Br J Anaesth. 2008;101(2):200-6.

12. Forget $\mathrm{P}$, Lois $\mathrm{F}$, de Kock M. Goal-directed fluid management based on the pulse oximeter-derived pleth variability index reduces lactate levels and improve fluid management. Anesth Analg. 2010;111(4):910-4.

13. Cesur S, Çardaközü T, Kuş A, Türkyılmaz N, Yavuz Ö. Comparison of conventional fluid management with PVI-based goal directed fluid management in elective colorectal surgery. J Clin Monit Comput. 2018; [Epub ahead of print].

14. Thiele RH, Rea KM, Turrentine FE, Friel $C M$, Hassinger $T E$, McMurry $T L$, Goudreau BJ, Umapathi BA, Kron IL, Sawyer RG, et al. Standardization of care: impact of an enhanced recovery protocol on length of stay, complications, and direct 30 costs after colorectal surgery. J Am Coll Surg. 2015;220:430-43.

15. Hengy B, Gazon M, Schmitt Z, Benyoub K, et al. Comparison between respiratory variations in pulse oximetry plethysmographic waveform amplitude and arterial pulse pressure during major abdominal surgery. Anesthesiology. 2012;117(5):973-80

16. Ganter MT, Geisen M, Hartnack S, Dzemali O, Hofer CK. Prediction of fluid responsiveness in mechanically ventilated cardiac surgical patients: the performance of seven different functional hemodynamic parameters. BMC Anesthesiol. 2018;18(1):55.

17. Gepts E, Shafer S, Camu F, Stanski D, Woestenborghs R, Van Peer A, Heykants J. Linearity of pharmacokinetics and model estimation of Sufentanil. Anesthesiology. 1995;83(6):1194-204.

18. Cai QF, Mi WD, Yuan WX. The ability of pleth variability index to predict fluid responsiveness in mechanically ventilated patients under general anaesthesia. Zhonghua Wai Ke Za Zhi. 2010;48(21):1628-32.

19. Benes J, Haidingerova L, Pouska J, Stepanik J, Stenglova A, Zatloukal J, Pradl R, Chytra I, Kasal E. Fluid management guided by a continuous non-invasive arterial pressure device is associated with decreased postoperative morbidity after total knee and hip replacement. BMC Anesthesiol. 2015;15:148.
20. Chow S, Shao J, Wang H. Sample Size Calculations in Clinical Research. 2nd ed. New York: Marcel Dekker; 2008

21. Konietschke F, Placzek M, Schaarschmidt F, et al. Nparcomp:an R software package for nonparametric multiple comparisons and simultaneous confidence intervals. J Stat Softw. 2015;64:1-17.

22. Brunner $E$, Munzel $U$. The nonparametric Behrens-fisher problem: asymptotic theory and a small-sample approximation. Biom J. 2000;1 (1):17-21.

23. Demirel I, Bolat E, Altun AY, Özdemir M, Beştaş A. Efficacy of goal-directed fluid therapy via Pleth variability index during laparoscopic roux-en-Y gastric bypass surgery in morbidly obese patients. Obes Surg. 2018;28(2):358-63.

24. Yu Y, Dong J, Xu Z, Shen H, Zheng J. Pleth variability index-directed fluid management in abdominal surgery under combined general and epidural anesthesia. J Clin Monit Comput. 2015;29:47-52.

25. Le Guen M, MD FA, Gayat E, Fischler M. The plethysmographic variability index does not predict fluid responsiveness estimated by esophageal Doppler during kidney transplantation a controlled study. Medicine. 2018;97:20.

26. Shelley KH, Murray WB, Chang D. Arterial-pulse oximetry loops: a new method of monitoring vascular tone. J Clin Monit. 1997;13:223-8.

27. Warnakulasuriya $S$, Davies $S$, Wilson R, Yates D. Comparison of esophageal Doppler and plethysmographic variability index to guide intraoperative fluid therapy for low-risk patients undergoing colorectal surgery. J Clin Anesth. 2016;34:600-8.

28. Bahlmann $H$, Hahn RG, Nilsson L. Pleth variability index or stroke volume optimization during open abdominal surgery: a randomized controlled trial. BMC Anesthesiol. 2018;18(1):115.

29. Joosten A, Raj Lawrence S, Colesnicenco A, Coeckelenbergh S, Vincent JL, Van der Linden P, Cannesson M, Rinehart J. Personalized versus Protocolized fluid management using noninvasive hemodynamic monitoring (Clearsight system) in patients undergoing moderate-risk abdominal surgery. Anesth Analg. 2018; [Epub ahead of print].

30. Stens J, Hering JP, van der Hoeven CWP, Boom A, et al. The added value of cardiac index and pulse pressure variation monitoring to mean arterial pressure-guided volume therapy in moderate-risk abdominal surgery (COGUIDE): a pragmatic multicentre randomised controlled trial. Anaesthesia. 2017;72(9):1078-87.

31. Holte $K$, Foss NB, Andersen J, Valentiner L, et al. Liberal or restrictive fluid administration in fast-track colonic surgery: a randomized, double-blind study. Br J Anaesth. 2007;99(4):500-8.

32. Broch O, Bein B, Gruenewald M, Höcker J, Schöttler J, Meybohm P, Steinfath $M$, Renner J. Accuracy of the pleth variability index to predict fluid responsiveness depends on the perfusion index. Acta Anaesthesiol Scand. 2011;55:686-93.

\section{Ready to submit your research? Choose BMC and benefit from:}

- fast, convenient online submission

- thorough peer review by experienced researchers in your field

- rapid publication on acceptance

- support for research data, including large and complex data types

- gold Open Access which fosters wider collaboration and increased citations

- maximum visibility for your research: over $100 \mathrm{M}$ website views per year

At BMC, research is always in progress.

Learn more biomedcentral.com/submissions 